\title{
Macroscopic impacts of cloud and precipitation processes on maritime shallow convection as simulated by a large eddy simulation model with bin microphysics
}

\author{
W. W. Grabowski ${ }^{1}$, L.-P. Wang ${ }^{2}$, and T. V. Prabha ${ }^{3}$ \\ ${ }^{1}$ National Center for Atmospheric Research, Boulder, Colorado, USA \\ ${ }^{2}$ Department of Mechanical Engineering, University of Delaware, Newark, Delaware, USA \\ ${ }^{3}$ Indian Institute of Tropical Meteorology, Pune, India \\ Correspondence to: W. W. Grabowski (grabow@ncar.ucar.edu) \\ Received: 3 June 2014 - Published in Atmos. Chem. Phys. Discuss.: 31 July 2014 \\ Revised: 18 November 2014 - Accepted: 19 December 2014 - Published: 27 January 2015
}

\begin{abstract}
This paper discusses impacts of cloud and precipitation processes on macrophysical properties of shallow convective clouds as simulated by a large eddy model applying warm-rain bin microphysics. Simulations with and without collision-coalescence are considered with cloud condensation nuclei $(\mathrm{CCN})$ concentrations of $30,60,120$, and $240 \mathrm{mg}^{-1}$. Simulations with collision-coalescence include either the standard gravitational collision kernel or a novel kernel that includes enhancements due to the small-scale cloud turbulence. Simulations with droplet collisions were discussed in Wyszogrodzki et al. (2013) focusing on the impact of the turbulent collision kernel. The current paper expands that analysis and puts model results in the context of previous studies. Despite a significant increase of the drizzle/rain with the decrease of CCN concentration, enhanced by the effects of the small-scale turbulence, impacts on the macroscopic cloud field characteristics are relatively minor. Model results show a systematic shift in the cloudtop height distributions, with an increasing contribution of deeper clouds for stronger precipitating cases. We show that this is consistent with the explanation suggested in Wyszogrodzki et al. (2013); namely, the increase of drizzle/rain leads to a more efficient condensate offloading in the upper parts of the cloud field. A second effect involves suppression of the cloud droplet evaporation near cloud edges in low$\mathrm{CCN}$ simulations, as documented in previous studies (e.g., Xue and Feingold, 2006). We pose the question whether the effects of cloud turbulence on drizzle/rain formation in shallow cumuli can be corroborated by remote sensing observa-
\end{abstract}

tions, for instance, from space. Although a clear signal is extracted from model results, we argue that the answer is negative due to uncertainties caused by the temporal variability of the shallow convective cloud field, sampling and spatial resolution of the satellite data, and overall accuracy of remote sensing retrievals.

\section{Introduction}

Impacts of atmospheric aerosols on cloud and precipitation processes continue to attract significant attention of the atmospheric science community. The main reason is the key role clouds play in the Earth climate system, with cloud modifications (either natural or anthropogenic) having an important but poorly understood effect. Cloud processes and their interactions remain difficult to represent in large-scale models of weather and climate because of the disparity between spatial and temporal scales at which cloud processes operate and scales that can be resolved by the large-scale models. For that reason, weather and climate models have to rely on uncertain parameterizations with the impact of cloud microphysics involving a "parameterization squared" conundrum, that is, effects of parameterized cloud microphysics considered in the context of parameterized clouds. A significantly better understanding can be developed by the application of highresolution models, such as cloud-system-resolving models or large eddy simulation (LES) models, especially when combined with bin microphysics. Such studies contribute to the 
understanding of the multiscale interactions between cloudscale and larger-scale processes, guide the development of improved parameterization schemes, and ultimately lead to more credible weather and climate simulations.

There is a long history of studies concerning indirect effects of atmospheric aerosols on cloud and precipitation processes in shallow boundary layer clouds. Perhaps the most obvious is the impact of the cloud condensation nuclei $(\mathrm{CCN})$ concentration on the albedo of a cloud field through its effect on the spectrum of cloud droplets. This is typically referred to as the first indirect aerosol effect or the Twomey effect (Twomey, 1974, 1977). More recently, the smaller sizes of cloud droplets in polluted shallow cumuli were argued to affect cloud dynamics through the impact on the rate of cloud droplet evaporation and evaporative cooling near cloud edges (e.g., Xue and Feingold, 2006). Smaller cloud droplets in polluted clouds also lead to a suppressed development of drizzle and rain via collisions-coalescence (e.g., Warner, 1968). This is referred to as the second indirect aerosol effect and it can potentially affect the abundance, extent, and lifetime of some types of clouds, such as stratocumulus or shallow convective clouds (e.g., Albrecht, 1989; Pincus and Baker, 1994). Rainout of cloud condensate was also argued to reduce the deepening of shallow convection layers (Stevens, 2007; Stevens and Seifert, 2008).

Although all these effects seem straightforward based on physical reasoning, their effects in realistic conditions (i.e., including interactions between cloud-scale and larger-scale processes) are difficult to quantify. This is because clouds feed back onto larger scales and modify the environment in which subsequent clouds develop. An extreme example, discussed in Grabowski (2006) and Grabowski and Morrison (2011), is the secondary role cloud microphysics play in the convective-radiative quasi-equilibrium. In the quasiequilibrium, the radiative destabilization of the atmosphere dictates the latent heating and surface precipitation, with the destabilization virtually unaffected by cloud microphysical processes (at least in the simulations discussed there). Arguably, this is one of many examples of the "buffering" of cloud effects in the climate problem as discussed in Stevens and Feingold (2009).

In this paper, we discuss results from LES model simulations of fields of shallow precipitating and non-precipitating convection, extending the analysis presented in Wyszogrodzki et al. (2013, hereinafter WGWA13). WGWA13 focused on the effects of small-scale cloud turbulence on the development of drizzle and rain by contrasting results from simulations applying the standard gravitational collision kernel and a novel kernel that included effects of smallscale cloud turbulence ("turbulent kernel" in short throughout this paper). The turbulent kernel significantly affected the development of drizzle/rain and led to a significant increase of the mean surface precipitation. As documented in idealized simulations in Sect. 5.1 of WGWA13, not only did the drizzle/rain form earlier in a single cloud when the turbu- lent kernel was used, but clouds that included effects of turbulence rained more on average. The latter was explained as a combination of microphysical and dynamical effects. The microphysical effect comes from earlier formation of drizzle/rain in the cloud life cycle (as suggested by previous idealized studies, e.g., Wang et al., 2006; Grabowski and Wang, 2009). This allows more cloud water to be converted into precipitation before the cloud dissipates. The dynamical effect involves an increased contribution of deeper clouds to the cloud population, an aspect further quantified by the analysis presented here.

The purpose of this paper is twofold. First, we present the analysis documenting the impact of cloud and precipitation processes on the macrophysical properties of the cloud field following the above discussion. If the model simulates a significant impact on the macrophysical cloud field properties, relatively straightforward cloud field observations can be used in support of simulated effects. Unfortunately, the analysis shows that the macrophysical effects remain relatively small. Second, we pose a question whether more sophisticated remote sensing observations (e.g., involving combinations of macrophysical and microphysical observations from space; cf. Suzuki et al., 2013) would be capable in lending support for the effects of small-scale cloud turbulence on the rain development. Again, the results presented herein suggest a rather negative answer.

The paper is organized as follows. The next section briefly discusses the numerical model and modeling setup, with details already presented in WGWA13. Section 3 presents analysis of model results focusing on the macroscopic impacts of cloud microphysics. In Sect. 4, examples of model results are shown that suggest a negative answer to the second question above. Section 5 provides a discussion of model results and concludes the paper.

\section{Numerical model and model setup}

This paper presents additional analyses of cloud field simulations presented in WGWA13. The fluid flow is calculated by the anelastic EULAG (EUlerian/LAGrangian) model (see Prusa et al., 2008, for a review and comprehensive list of references). The flow model is combined with the sizeresolving representation of warm-rain microphysical processes that include droplet activation, droplet growth by water vapor diffusion and by collision-coalescence (Grabowski and Wang, 2009; Grabowski et al., 2011).

The model setup is based on the Barbados Oceanographic and Meteorological Experiment (BOMEX; Holland and Rasmusson, 1973) as used in the model intercomparison study described in Siebesma et al. (2003). Lower troposphere structure features $1 \mathrm{~km}$ deep trade-wind convection layer overlaying the $0.5 \mathrm{~km}$ deep mixed layer near the ocean surface, covered by the $0.5 \mathrm{~km}$ deep trade-wind inversion and free troposphere aloft. Weak shear (around $1 \mathrm{~m} \mathrm{~s}^{-1}$ per km) is imposed 
throughout the convection layer and above. The quasi-steady conditions are maintained by prescribed large-scale subsidence, large-scale moisture advection, surface heat fluxes, and radiative cooling. The model grid length is $50 / 20 \mathrm{~m}$ in the horizontal/vertical direction. The domain size is $6.4 \times$ $6.4 \mathrm{~km}^{2}$ in the horizontal and $3 \mathrm{~km}$ in the vertical.

Simulations are performed assuming four CCN concentrations, constant in time and space, and equal to 30,60 , 120 , and $240 \mathrm{mg}^{-1}$. Such a range represents extremely clean to weakly polluted cloud conditions for subtropical shallow convective clouds. As in WGWA13, the simulations are referred to as N30, N60, N120, and N240. Three simulations were performed for each $\mathrm{CCN}$ concentration. The first simulation, referred to as NOCOAL, excludes effects of collision-coalescence; it only considers activation of CCN and diffusional growth/evaporation of cloud droplets as in Wyszogrodzki et al. (2011). The second simulation includes collision-coalescence and drizzle/rain formation by applying the standard gravitational collision kernel; it is referred to as GRAV. Finally, simulation TURB applies a collision kernel that includes effects of small-scale cloud turbulence as presented in WGWA13. Model results are saved as either horizontally averaged profiles of selected variables every $1 \mathrm{~min}$ or 3-D snapshots every $5 \mathrm{~min}$. Most of the analysis presented here is based on the last $3 \mathrm{~h}$ of the $6 \mathrm{~h}$ long simulations.

\section{Results}

The simulations feature an increasing amount of drizzle/rain with decreasing CCN concentrations (from N240 down to N30) for the GRAV and TURB cases as documented in Figs. 14 and 15 in WGWA13 and Table 1 here, with NOCOAL simulations featuring no drizzle/rain. Despite these differences, the macroscopic properties of the cloud field are affected in a rather minor way. Arguably, this should not be surprising considering a low cloud cover (around 0.2; see Table 1) and still relatively small surface precipitation rate even for the strongest-raining TURB N30 case (mean surface rain rate around $0.01 \mathrm{~mm} \mathrm{~h}^{-1}$ or $7 \mathrm{~W} \mathrm{~m}^{-2}$ ). However, the impacts are consistent with those reviewed in the introduction and suggested in WGWA13 as documented in the following discussion.

\subsection{Cloud-top height distributions}

Section 5.1 in WGWA13 discussed idealized single-cloud simulations that helped to explain the cloud field simulation results. The idealized simulations applied either the standard gravitational collision kernel or the novel turbulent kernel, and used two environmental soundings, either with or without strong inversion that limited vertical cloud development. With the inversion, clouds developed similarly in simulations with either kernel. Precipitation enhancement for the turbulent kernel was argued to come from the microphysical im-
Table 1. Domain-averaged $6 \mathrm{~h}$ surface rain accumulation (in $\mathrm{mm}$ ) and mean cloud cover from the last $3 \mathrm{~h}$ for all simulations discussed in this paper. Cloud cover is defined as a fraction of model columns featuring at least one grid volume with the cloud water mixing ratio larger than $0.01 \mathrm{~g} \mathrm{~kg}^{-1}$. The numbers in brackets for the cloud cover are standard deviations of the $3 \mathrm{~h}$ time evolutions.

\begin{tabular}{lrrr}
\hline Simulation set & $\begin{array}{r}\text { NOCOAL } \\
\text { surface rain } \\
\text { accumulation }\end{array}$ & GRAV & TURB \\
\hline N30 & 0 & 0.012 & 0.050 \\
N60 & 0 & 0.001 & 0.013 \\
N120 & 0 & 0 & 0.002 \\
N240 & 0 & 0 & 0 \\
\hline & cloud cover & & \\
\hline N30 & $0.194(0.018)$ & $0.194(0.016)$ & $0.191(0.022)$ \\
N60 & $0.178(0.024)$ & $0.190(0.020)$ & $0.187(0.023)$ \\
N120 & $0.175(0.013)$ & $0.178(0.016)$ & $0.171(0.021)$ \\
N240 & $0.170(0.015)$ & $0.170(0.016)$ & $0.168(0.019)$ \\
\hline
\end{tabular}

pact alone, that is, more rapid drizzle/rain development when the turbulent collision kernel was used. In contrast, simulations without the inversion combined microphysical and dynamical enhancements, because the cloud in the simulation applying turbulent kernel was able to reach higher levels and thus provided more condensate for precipitation formation. WGWA13 argued that the dynamical enhancement came from a more efficient condensate offloading when the turbulent collision kernel was used.

The condensate offloading mechanism in low-CCN precipitating cases and faster evaporation of cloud droplets in high-CCN non-precipitating cases (Xue and Feingold, 2006) taken together explain cloud-top height distributions in cloud field simulations. The distributions for N240 and N30 simulations are compared in Fig. 1, with N120 and N60 simulations somewhere between those shown. As in WGWA13, cloud-top height is defined on a column-by-column basis as the level at which the liquid (cloud and rain/drizzle) water path integrated downwards from the upper model boundary reaches $10 \mathrm{~g} \mathrm{~m}^{-2}$. Note that such a definition typically leads to several values of the cloud-top height for a single cloud rather than just a single value. It is also worth pointing out that the histograms can be used to deduce the fractional area coverage of cloudy columns with a given cloud-top height and hence with the cloud-top temperature. Snapshots of the cloud field for hours 3-6 are used to construct the histograms applying a $100 \mathrm{~m}$ height bin. The number of cloudy columns that are identified by the algorithm for each simulation is also shown in the panels.

For all N240 simulations, the histograms are similar and feature two peaks, with a larger/smaller mode for shallow/deep clouds. The number of cloudy columns differs between NOCOAL, GRAV and TURB simulations by just 

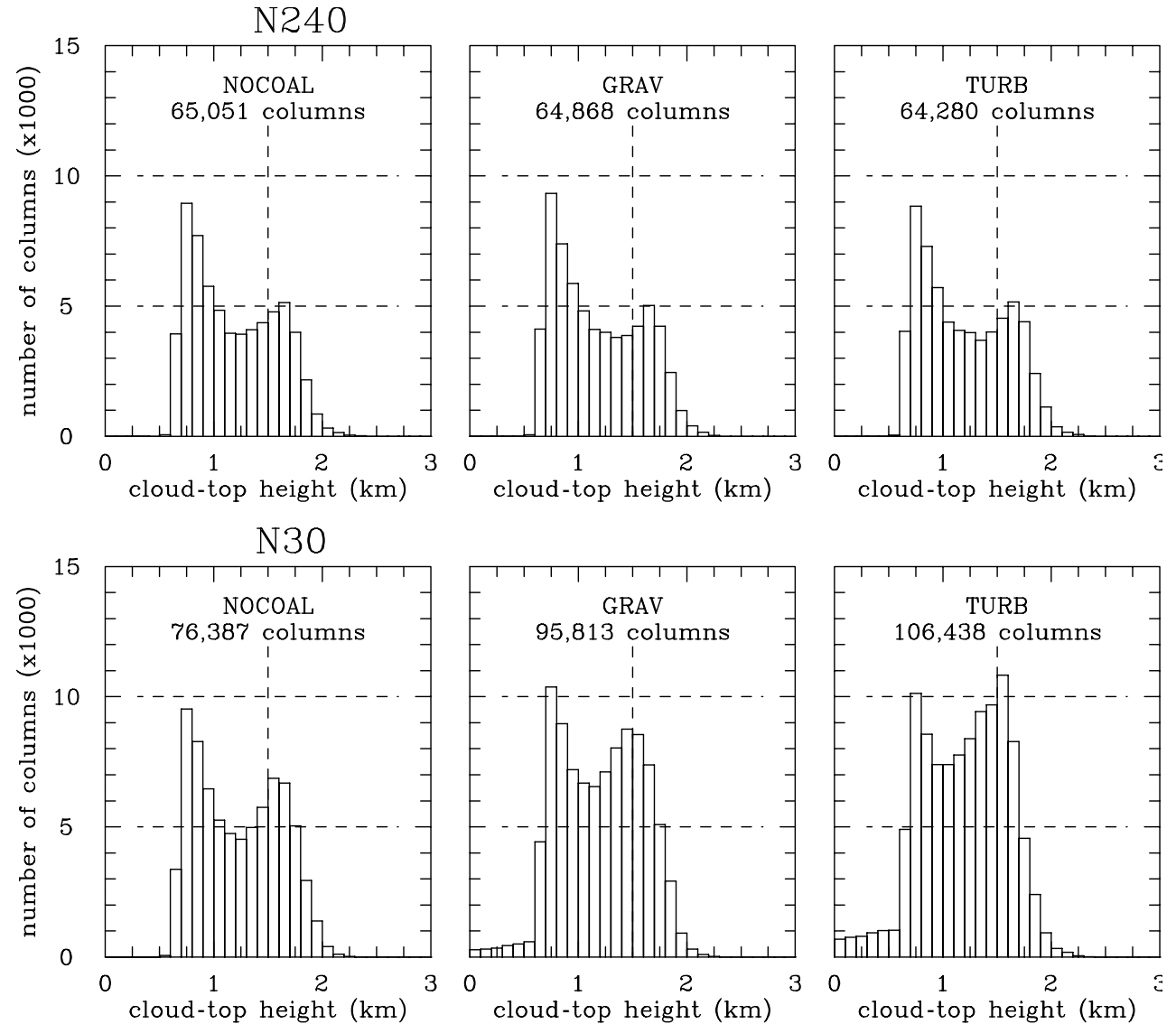

Figure 1. Histograms of the cloud-top height for NOCOAL, GRAV and TURB simulations N240 and N30 for the last $3 \mathrm{~h}$ of model simulations. The bin width is $100 \mathrm{~m}$. The number of model columns included in each histogram is shown in the panels.

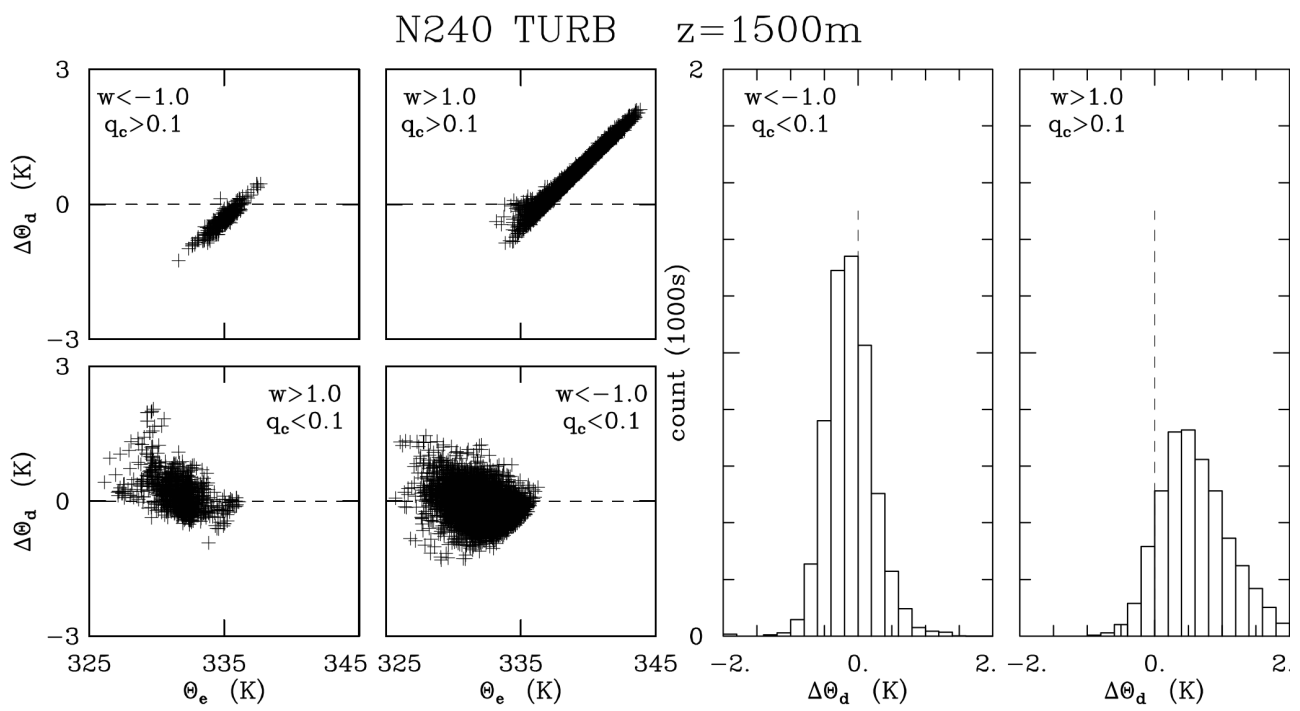

Figure 2. Left four panels: scatterplots of $\Delta \theta_{\mathrm{d}}$ vs. $\theta_{\mathrm{e}}$ for points at height of $1500 \mathrm{~m}$ separated into different regions depending on the vertical velocity $w$ and cloud water mixing ratio $q_{\mathrm{c}}$. Right two panels: histograms of $\Delta \theta_{\mathrm{d}}$ for points corresponding to cloud-edge downdrafts and cloud updrafts applying $0.2 \mathrm{~K}$ bins. Results for N240 TURB simulation at $1500 \mathrm{~m}$ height. 


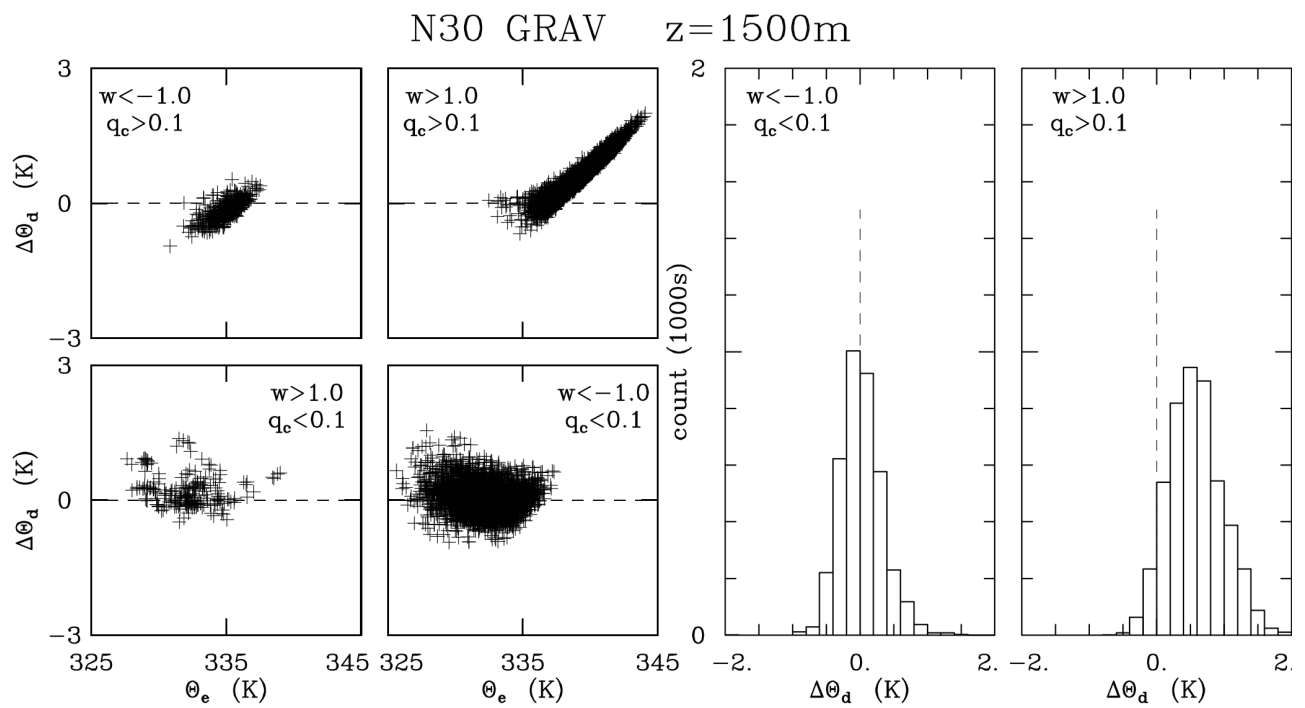

Figure 3. As Fig. 2, but for the N30 GRAV simulation.

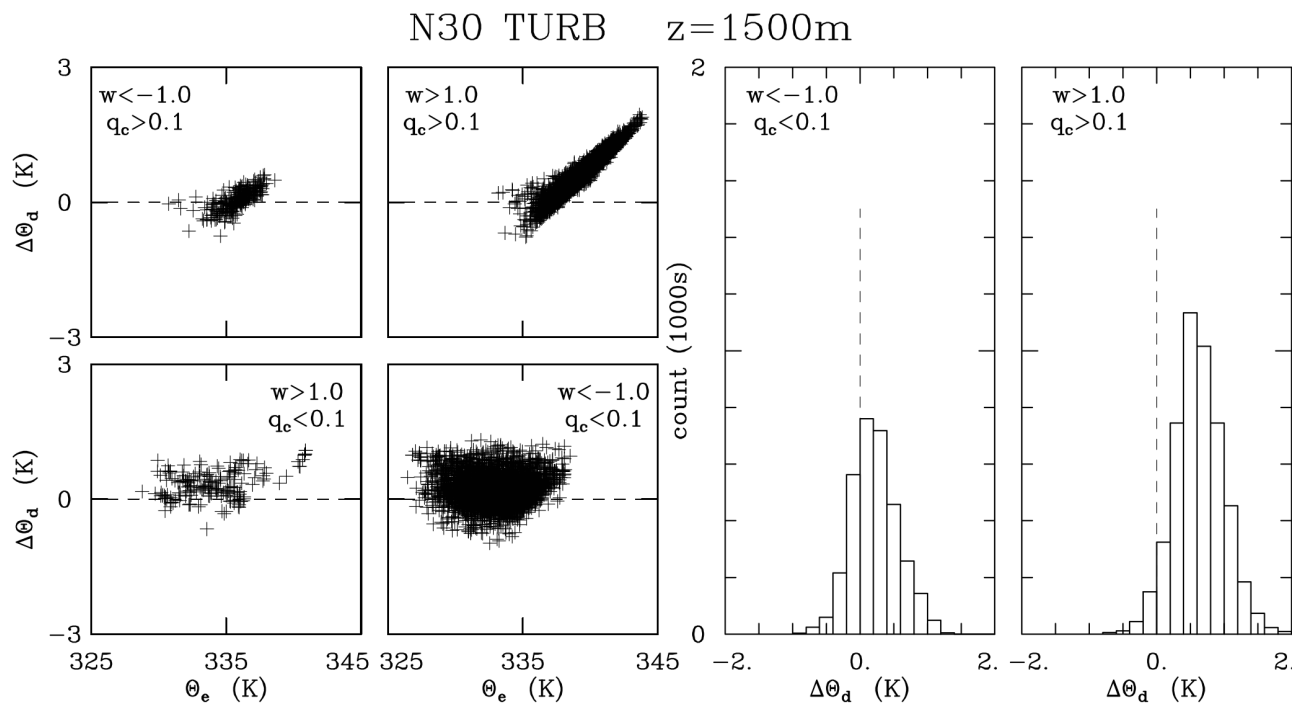

Figure 4. As Fig. 2, but for the N30 TURB simulation.

a few percent. For N30, the histogram for NOCOAL simulation is similar to the $\mathrm{N} 240$, but the number of columns is larger by about $15 \%$. This is consistent with smaller cloud fractions and smaller mean cloud cover (cf. Table 1) for the N240 cases as discussed later in the paper. Arguably this comes from the smaller size of cloud droplets and thus their more rapid evaporation near cloud edges (Xue and Feingold, 2006). N30 GRAV and TURB histograms show a gradual increase of the mode corresponding to higher cloud tops and an increasing number of model columns included in the histogram. The former can be argued to result from the dynamical impact of turbulent droplet collisions on the cloud field through the condensate offloading mechanism. The increase of the number of columns comes partially from the presence of rain near the surface with no cloud above as documented by bins below the typical cloud base around $700 \mathrm{~m}$. These bins are empty in the non-precipitating cases, but become nonzero in N30 GRAV and TURB histograms. However, the increases from NOCOAL to GRAV and from GRAV to TURB in N30 cannot be explained by contributions from histogram bins below $700 \mathrm{~m}$ alone. The number of columns with cloud tops above $1 \mathrm{~km}$ systematically increases from NOCOAL to TURB; this implies a significant dynamical impact associated with precipitation development and fallout through the condensate offloading. 


\subsection{Liquid water, updraft, and cloud buoyancy distributions}

Effects of condensate offloading and cloud-edge evaporation may be difficult to identify in cloud field simulations featuring ensembles of clouds at various stages of their life cycle. This is illustrated by the next four figures that show an analysis of model results for the last $3 \mathrm{~h}$ of the N240 and N30 simulations. First, model points at the height of $1500 \mathrm{~m}$ (at or slightly below the higher-cloud-top modes in Fig. 1) are partitioned into four groups depending on the cloud water mixing ratio $\left(q_{\mathrm{c}}\right.$; either larger or smaller than $\left.0.1 \mathrm{~g} \mathrm{~kg}^{-1}\right)$ and the vertical velocity $\left(w\right.$; either larger than $1 \mathrm{~m} \mathrm{~s}^{-1}$ or smaller than $-1 \mathrm{~m} \mathrm{~s}^{-1}$ ). Points with $q_{\mathrm{c}}>0.1 \mathrm{~g} \mathrm{~kg}^{-1}$ and $w>$ $1 \mathrm{~m} \mathrm{~s}^{-1}$ (hereafter "cloud updrafts") may be considered as part of an actively growing cloud. In contrast, points with $q_{\mathrm{c}}<0.1 \mathrm{~g} \mathrm{~kg}^{-1}$ and $w<-1 \mathrm{~m} \mathrm{~s}^{-1}$ represent significantly descending volumes with either a trace or no cloud water, arguably in the vicinity of cloud edges (hereafter "cloud-edge downdrafts"). Descending cloudy volumes $\left(q_{\mathrm{c}}>0.1 \mathrm{~g} \mathrm{~kg}^{-1}\right.$ and $w<-1 \mathrm{~m} \mathrm{~s}^{-1}$ ) are likely part of the toroidal circulations near the cloud top (e.g., Grabowski and Clark, 1993; Damiani and Vali, 2007), whereas points with $q_{\mathrm{c}}<0.1 \mathrm{~g} \mathrm{~kg}^{-1}$ and $w>1 \mathrm{~m} \mathrm{~s}^{-1}$ correspond to ascending strongly diluted volumes. Second, the equivalent potential temperature $\theta_{\mathrm{e}}$ and the density potential temperature $\left(\theta_{\mathrm{d}}\right.$; the virtual temperature that includes the impact of the liquid water) for the four groups of points are applied to create $\theta_{\mathrm{d}}$ vs. $\theta_{\mathrm{e}}$ scatterplots and $\theta_{\mathrm{d}}$ histograms. The four scatterplots are shown in left panels of Figs. 2, 3, and 4 (with $\theta_{\mathrm{d}}$ plotted as a deviation from the initial temperature and moisture profiles, $\Delta \theta_{\mathrm{d}}$, as used in the model's buoyancy), whereas histograms of $\Delta \theta_{\mathrm{d}}$ for cloud updrafts and cloud-edge downdrafts are shown in the right panels. One might anticipate systematic differences in the scatterplots and histograms depending on the assumed $\mathrm{CCN}$ concentration (and thus the cloud droplet concentration) and either gravitational or turbulent collision kernel for precipitating cases.

As shown in Figs. 2, 3, and 4, scatterplots of $\Delta \theta_{\mathrm{d}}$ vs. $\theta_{\mathrm{e}}$ are similar for the N240 and N30 simulations. Points corresponding to cloud updrafts $\left(q_{\mathrm{c}}>0.1 \mathrm{~g} \mathrm{~kg}^{-1}, w>1 \mathrm{~m} \mathrm{~s}^{-1}\right)$ are aligned in such a way that high $\Delta \theta_{\mathrm{d}}$ values correspond to high $\theta_{\mathrm{e}}$ values. The highest $\theta_{\mathrm{e}}$ values are for parcels with undiluted air from near the surface (this is confirmed by the analysis of the surface-layer $\theta_{\mathrm{e}}$; not shown) and they also correspond to the highest buoyancies. Smaller buoyancies represent air parcels that have been diluted (i.e., smaller $\theta_{\mathrm{e}}$ ). Arguably, these undiluted or weakly diluted volumes are regions where drizzle/rain is initiated (cf. Khain et al., 2013; Cooper et al., 2013). Points corresponding to cloud-edge downdrafts $\left(q_{\mathrm{c}}<0.1 \mathrm{~g} \mathrm{~kg}^{-1}, w<-1 \mathrm{~m} \mathrm{~s}^{-1}\right)$ feature lower $\theta_{\mathrm{e}}$ (i.e., more entrainment) and the buoyancy scattered around zero. The other two groups of points show similar patterns between the N30 and N240 simulations.
The key difference between N30 and N240 simulations is documented in the histograms shown on the right-hand side of Figs. 2, 3, and 4. For the cloud updrafts, the peak in the distribution increases as one moves from N240 to GRAV N30 and then to TURB N30, and the number of points comprising the histogram is around 4500, 4800, and 4900 for Figs. 2, 3 , and 4 , respectively, with a similar mean buoyancy $\left(\Delta \theta_{\mathrm{d}}\right.$ around $0.6 \mathrm{~K}$ ). The opposite is true for the cloud-edge downdrafts: the peak in the distribution is smaller. For the N30 cases, the mean value is larger ( 0.2 vs. $-0.1 \mathrm{~K}$ for N30 TURB vs. N240 TURB), and there is a significantly smaller number of points comprising the histogram (3200/5600 for TURB N30/N240). The latter suggests that the ease of droplet evaporation in the N240 case affects not only the mean negative buoyancy at cloud edges, but also the width of cloud-edge downdrafts.

Results of an additional analysis documenting differences in properties of cloud updrafts between N30 GRAV and TURB simulations are shown in Fig. 5. The figure shows joint and marginal histograms for the updraft velocity and liquid water mixing ratio $\left(q_{\mathrm{c}}+q_{\mathrm{r}}\right)$ at the height of $1500 \mathrm{~m}$. The differences between the two cases are small but distinct. The joint histogram for the TURB case has more data points with updrafts between 1 and $3 \mathrm{~m} \mathrm{~s}^{-1}$ and liquid water between 1 and $2 \mathrm{~g} \mathrm{~kg}^{-1}$. This is reflected in the shape of the liquid water marginal histogram that features an apparent shift of the maximum towards higher values for the TURB case. This may seem to contradict the condensate offloading mechanism. However, one needs to keep in mind that the data used to create Fig. 6 come from many clouds at various stages of their life cycle and the shift of the peak may reflect a modification of cloud statistics and not the change of a single cloud's properties during the cloud evolution. For instance, offloading of the cloud condensate through more efficient collision-coalescence below $1500 \mathrm{~m}$ in the TURB case should lead to an increased number of clouds that reach this level and result in the shift of the distribution, similarly to the change of the cloud-top height distribution (cf. Fig. 1). Such an argument is consistent with about $3 \%$ increase of the number of data points from GRAV to TURB. Moreover, more efficient offloading of the cloud condensate above $1500 \mathrm{~m}$ and an increased downward flux of drizzle/rain from above may also contribute to the shift of the peak. Marginal distributions of the updraft velocity are similar between GRAV and TURB cases. Overall, the results document rather subtle changes in the cloud field statistics in response to changes in the $\mathrm{CCN}$ concentration.

\subsection{Cloud fraction profiles}

Figure 6 presents cloud fraction profiles for selected simulations. Cloud fraction at a given level is defined as the fraction of model grid volumes with the cloud water mixing ratio larger than $0.01 \mathrm{~g} \mathrm{~kg}^{-1}$. The comparison between the NOCOAL N30 and N240 simulations (top panels) illus- 

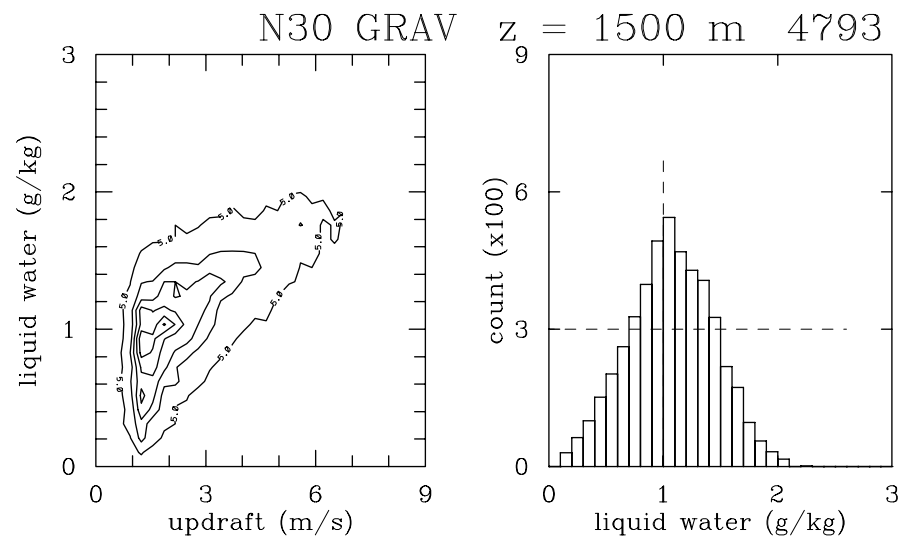

points
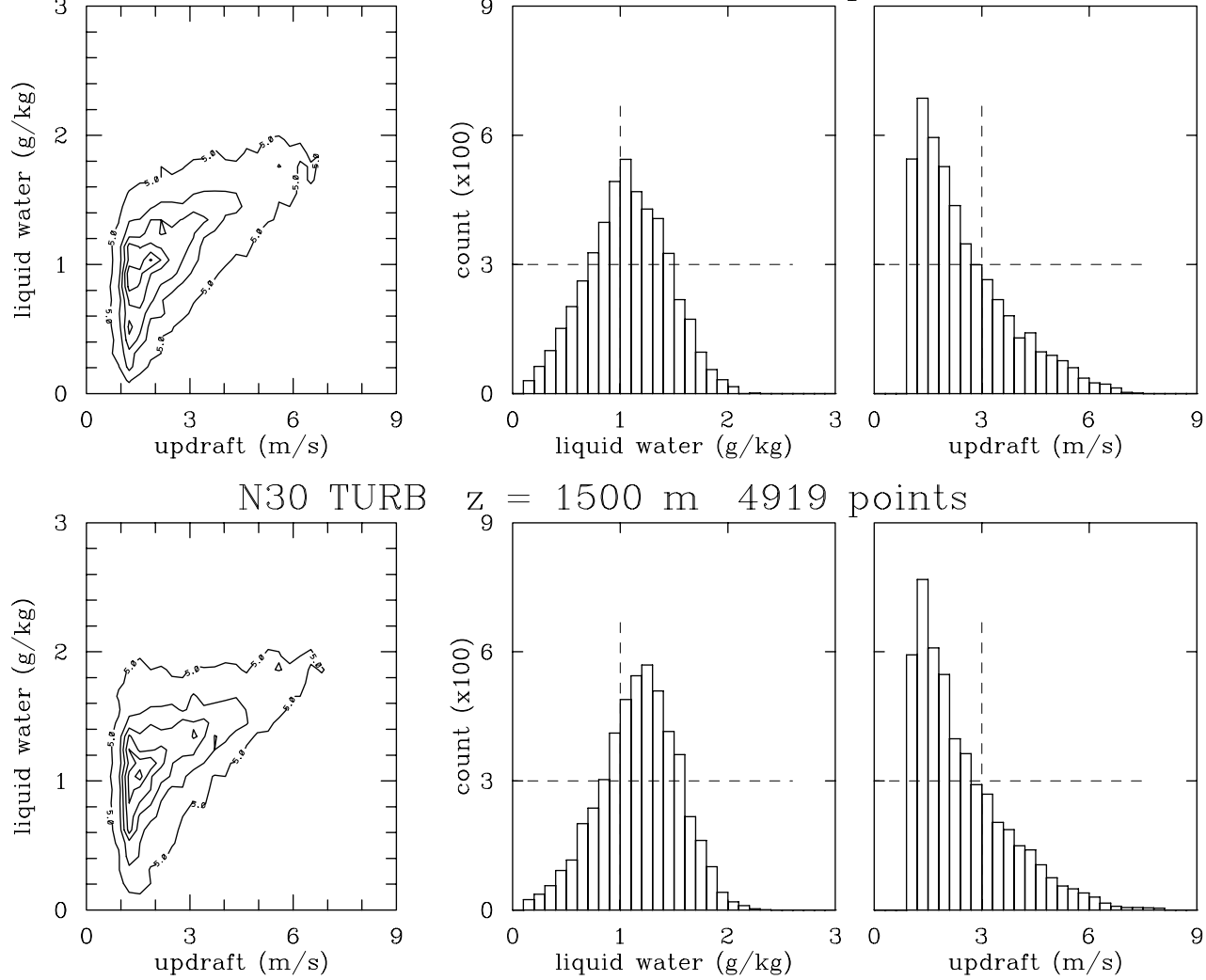

Figure 5. Left two panels: joint histograms of the updraft velocity and liquid water mixing ratio for cloud updrafts $\left(q_{\mathrm{c}}>0.1 \mathrm{gkg} \mathrm{kg}^{-1}\right.$ and $w>1 \mathrm{~m} \mathrm{~s}^{-1}$ ) at height of $1500 \mathrm{~m}$. Right four panels: marginal histograms for the liquid water and updraft velocity obtained from joint histograms. Histograms are generated applying 30 bins for the liquid water and updraft velocity with the bin width of $0.1 \mathrm{gkg}^{-1}$ and $0.3 \mathrm{~m} \mathrm{~s}^{-1}$. N30 GRAV and TURB simulations. Dashed lines in marginal histograms highlight the differences.

trates the impact of the mean droplet size on the evaporation of cloud water near cloud edges (Xue and Feingold, 2006). Since cloud droplets are smaller in the N240 simulation, they evaporate more readily and this leads to the lower cloud fraction, all other things being equal. However, when precipitation processes are allowed, the NOCOAL N30 cloud fraction is significantly different from the TURB N30 case (middle panels). Arguably, this comes from the removal of cloud water due to drizzle or rain that can be argued to decrease/increase cloud fraction in upper/lower parts of the cloud field in TURB N30 as shown in the middle panels. Finally, the bottom panels compare full-physics (i.e., TURB) simulations for the N240 and N30 cases. The difference between the two cases is consistent with the effects discussed above, that is, faster evaporation of cloud droplets near cloud edges in the $\mathrm{N} 240$ case and removal of drizzle/rain from the upper parts of the cloud field in the N30 case.

Figure 6 does not compare N30 TURB and GRAV simulations because the differences are small and arguably not statistically significant. The mean cloud cover for all simulations is shown in Table 1. The table shows that the cloud cover decreases with the increase of CCN (from about 0.19 for N30 to 0.17 for N240), and also seems to decrease when precipitation is allowed to develop in GRAV and TURB simulations. However, the differences do not appear statistically significant, because the standard deviation of the temporal variability (shown in the brackets in the table) is comparable to the difference between different simulations. This highlights the fundamental problem when comparing model simulations applying different microphysical schemes or the same scheme with different scheme parameters. Such parallel simulations evolve differently even if they are initiated from the same initial conditions and one needs to separate the impact of the microphysics scheme from the effects of the natural variability. We will return to this issue in the discussion section.

\section{Prospects for remote sensing in evaluation of turbulence effects on warm-rain initiation}

Because of the volumes of data available from remote sensing (e.g., ground- or satellite-based radar), one might hope that the impact of the small-scale turbulence on warm-rain 

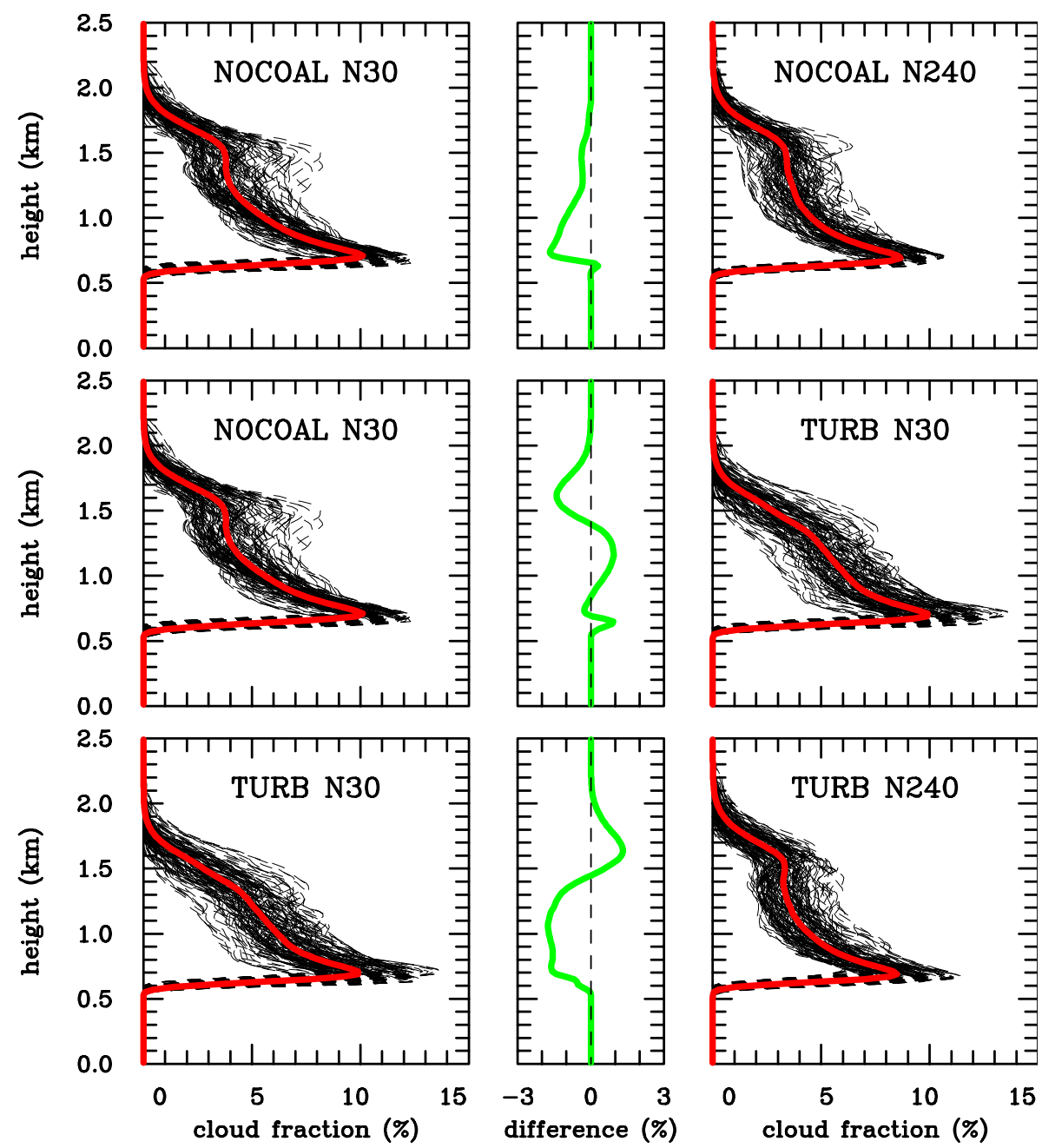

Figure 6. Cloud fraction profiles for selected simulations. Dashed black lines are profiles every minute for the last $3 \mathrm{~h}$ and the red solid lines are average profiles for that period. The middle panels (green lines) show differences between the right and the left mean profiles.

initiation can be corroborated by applying such data sets. However, analysis of the model data presented below casts serious doubt on such prospects, mostly because of the issues related to the precise estimate of aerosol conditions and the effects of the cloud life cycle, the latter especially important for shallow convection.

Figure 7 shows the probability of the $0.1 \mathrm{~mm} \mathrm{~h}^{-1}$ precipitation (POP hereafter) for TURB and GRAV simulations N30 and N120. POP is estimated as a fraction of the model columns with a given cloud water path (CWP) that have drizzle/rain water anywhere in the column with the corresponding precipitation rate exceeding the $0.1 \mathrm{~mm} \mathrm{~h}^{-1}$ threshold. Data points for N60 simulations are between N120 and N30 shown in the figure. POPs for the N240 TURB and GRAV cases are close to zero and reach about 0.1 for cloud water path of $1 \mathrm{~kg} \mathrm{~m}^{-2}$. The upper three CWP bins in Fig. 7 may not be statistically significant because of a small number of model columns and uncertain POP estimation. The figure was constructed in an attempt to follow the analysis of the A-Train data reported in Suzuki et al. (2013; Fig. 1 therein). Suzuki et al. (2013; hereinafter SSL13) obtained the cloud water path from MODIS and the probability of precipitation from CloudSat. Since the goal of SSL13's study is to compare the observations to high-resolution general circulation model simulations, the data shown in Fig. 1 of SSL13 include additional spatial averaging to match the $7 \mathrm{~km}$ model horizontal grid length. However, even at their native resolution (footprint of about $1.8 \mathrm{~km}$ ) CloudSat observations are difficult to compare with $50 \mathrm{~m}$ horizontal grid length large eddy simulations discussed here. It follows that only a very general comparison with observations reported in SSL13 is possible.

Figure 7 shows, in agreement with Fig. 1 in SSL13, that POP increases with the cloud water path, as one might anticipate, and it differs significantly between various simulations. The dependence on the CCN concentration is signifi- 


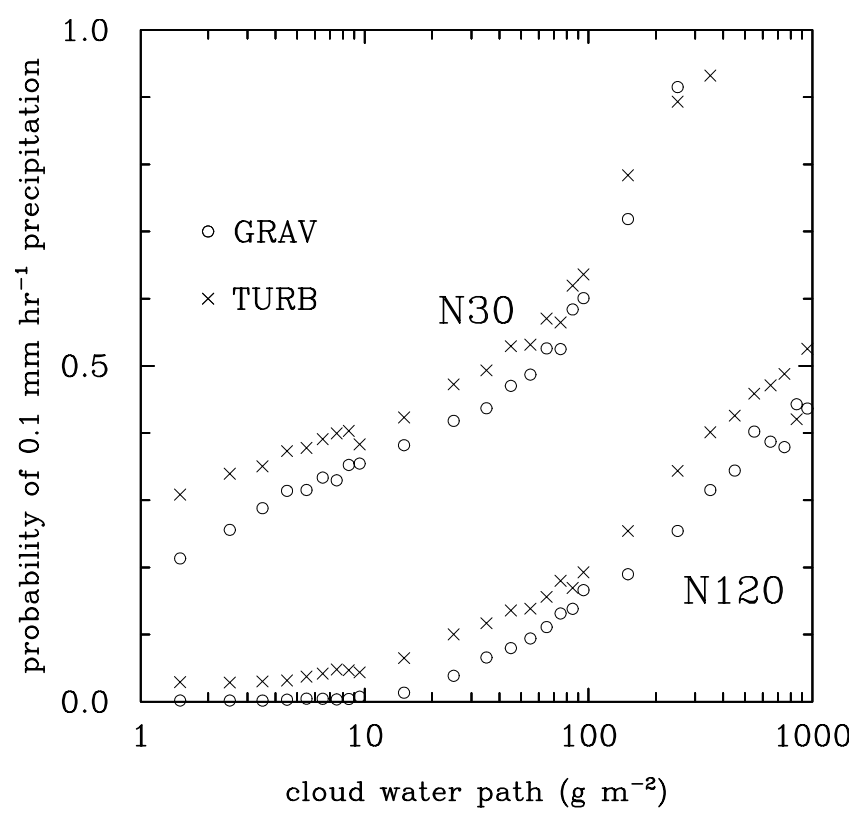

Figure 7. Probability of the $0.1 \mathrm{~mm} \mathrm{~h}^{-1}$ precipitation for TURB and GRAV simulations N30 and N120 as a function of the cloud water path for the last $3 \mathrm{~h}$ of the simulations.

cantly stronger than shown in Fig. 1 of SSL13. Various factors (e.g., differences in the spatial resolution of model and observations, uncertain relationship between $\mathrm{CCN}$ concentration used here and aerosol index applied in SSL13) undoubtedly contribute to the difference. The figure also shows that POP is higher in TURB cases when compared to GRAV for a given cloud water path. However, the increase is rather small (say, below $10 \%$ ), an impact arguably difficult to quantify by satellite or ground radar observations.

Figure 8 compares the frequency of occurrence of the cloudy column optical thickness $\tau$ (calculated using the model bin microphysics output) and the column effective radius (calculated as $3 W / 2 \rho_{\mathrm{w}} \tau$, where $W$ is the cloud water path and $\rho_{\mathrm{w}}$ is the water density) for N240 and N30 simulations. The frequency distributions for the optical thickness differ between N240 and N30 (e.g., different slope of the distribution tail), but are similar between the three simulations for each CCN concentration. N30 simulations show smaller averaged values, between 3.7 and 4.6, vs. between 8.7 and 8.8 for $\mathrm{N} 240$, in agreement with lower droplet concentrations and larger droplet sizes for N30. Precipitation processes show a rather insignificant impact because of the small differences between NOCOAL and TURB cases. Histograms of the effective radius frequency of occurrence for NOCOAL simulations show only values corresponding to the cloud droplet radii, larger for the N30 simulation, as expected. For N240 GRAV, the frequency of occurrence is similar to NOCOAL simulation. Only in the N240 TURB case, a relatively insignificant tail of values larger than $20 \mu \mathrm{m}$ is present. For N30 GRAV and TURB simulations, the frequency of occur- rence extends to the effective radius of $100 \mu \mathrm{m}$ (and beyond; not shown), with slightly larger frequencies for radii larger that $50 \mu \mathrm{m}$ in the TURB case. These results again suggest that applying satellite observations (e.g., such as used in SSL13) to support the simulated impact of small-scale cloud turbulence on warm-rain development may be difficult.

The final point above is further supported by an additional analysis of the warm-rain initiation in simulated clouds. Only GRAV and TURB simulations are considered, and joint histograms of the maximum radar reflectivity and the cloud-top mean droplet radius (both for a given cloudy column) are constructed from snapshots of 3-D model data. The premise of such an analysis lies in the expectation that, for given aerosol conditions, clouds that have larger droplets near their tops produce drizzle/rain more readily (e.g., Rosenfeld and Gutman, 1994; Rosenfeld, 2000; Pawlowska and Brenguier, 2003; Khain et al., 2013). However, for rapidly evolving shallow convective clouds, such an argument is likely valid only when the cloud life cycle is considered. In other words, the maxima of the cloud-top radius and the radar reflectivity should be taken over the cloud life cycle, not for a given cloud scene that features clouds at various stages of their life cycle. It follows that analyzing cloud field snapshots with clouds at various stages of their life cycle should result in a significant scatter. Such an expectation is consistent with the data shown in Figs. 9 and 10 that present joint histograms of the radar reflectivity and cloud-top radius for all cloudy columns from the N240 and N30 cases, respectively. For the N240 cases (Fig. 9), the relationship between the maximum radar reflectivity and the cloud-top droplet radius is relatively tight, with small scatter of the data points. The mean relationship, shown as the solid thick line, is quite similar between GRAV and TURB cases. Radar reflectivity corresponding to the onset of precipitation (i.e., $-15 \mathrm{dBz}$ as used in SSL13) gives the mean cloud-top radius that is only slightly smaller for the TURB case, 11.7 vs. $12.4 \mu \mathrm{m}$. For the N30 case (Fig. 10), the joint histogram is shifted upwards and to the right when compared to N240 (i.e., towards larger cloud droplets and higher radar reflectivities), with a significant scatter. The latter is most likely because of the cumulus life cycle as argued above. However, the relationship is still relatively tight up to the drizzle onset at $-15 \mathrm{dBz}$, again with the TURB cloud-top radius slightly smaller than in the GRAV case.

Figure 11 shows the mean cloud-top radius required to reach the $-15 \mathrm{dBz}$ threshold derived as illustrated in Figs. 9 and 10 for all GRAV and TURB simulations. The increase of the cloud-top radius from about $12 \mu \mathrm{m}$ for $\mathrm{N} 240$ to about $18 \mu \mathrm{m}$ for $\mathrm{N} 30$ is consistent with previous observations and idealized modeling studies (for instance, compare data presented in Table 3 and in Fig. 8 in Van Zanten et al. (2005); Table 5 in Grabowski and Wang (2009); and accompanying discussion). Arguably, this reflects the fact that drizzle/rain formation is a complex problem involving a combination of the threshold behavior and Lagrangian statistics. The former 

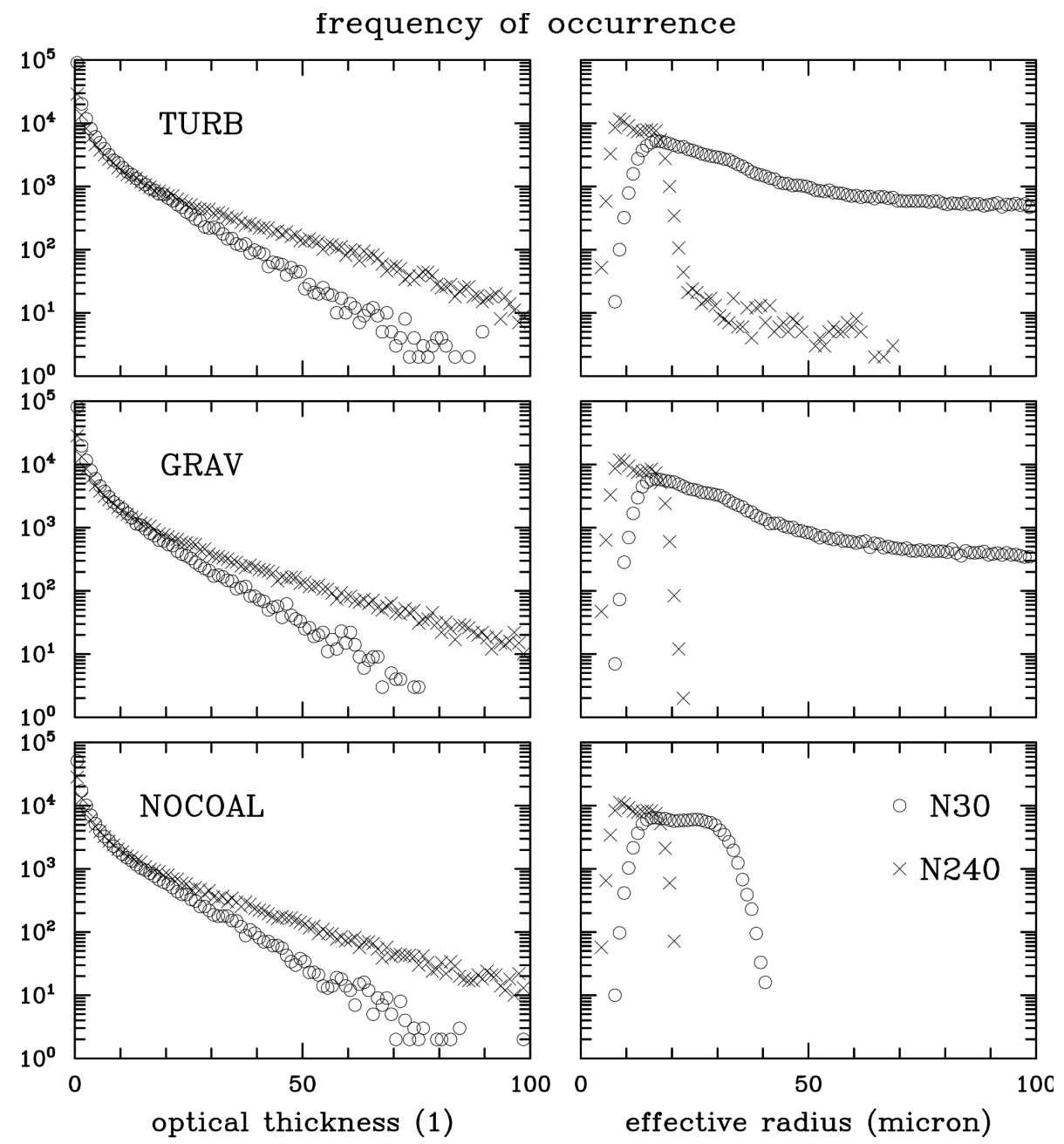

Figure 8. Frequency of occurrence of the optical thickness (left panels) and column effective radius (right panels) for last $3 \mathrm{~h}$ of $\mathrm{N} 30$ and N240 simulations.

is because the onset of significant droplet collisions is only possible once the mean droplet radius reaches values above $10 \mu \mathrm{m}$, mostly because of the low collision efficiencies for smaller droplets. The latter is because the evolution of the droplet spectrum after the threshold is reached still depends on additional parameters such as the mean droplet concentration that affects the frequency of collisions. Relatively small differences between the mean cloud-top radii at the onset of precipitation for GRAV and TURB simulations can be easily offset by changes in the aerosol conditions, not to mention complications associated with the effects of $\mathrm{CCN}$ chemical composition and size distribution, all excluded from this study by the details of the bin microphysics design.

\section{Discussion}

This paper presents results of additional analyses of large eddy simulations reported in Wyszogrodzki et al. (2013;
WGWA13). WGWA13 studied the impact of turbulent enhancement of the gravitational collision kernel on drizzle and rain from a field of shallow cumuli assuming the $\mathrm{CCN}$ concentration of $30,60,120$, and $240 \mathrm{mg}^{-1}$. WGWA13 showed that the impact involves two distinct effects. First, the earlier formation of drizzle in individual clouds when the turbulent kernel is used allows more cloud water to be converted to drizzle/rain throughout the cloud life cycle. Second, more rain from otherwise identical clouds leads to the feedback between cloud microphysics and cloud dynamics through the condensate offloading and an increase of cloud buoyancy in the upper parts of shallow cumuli. The feedback impacts the mean distribution of precipitating cloud tops, with larger contribution of deeper clouds when the turbulent collision kernel is used. We added here simulations with the same CCN concentrations as in WGWA13 but without collision-coalescence (e.g., as in Wyszogrodzki et al., 2011). The initial goal for this study was to quantify the impacts of the cloud and precipitation processes on macrophysical prop- 

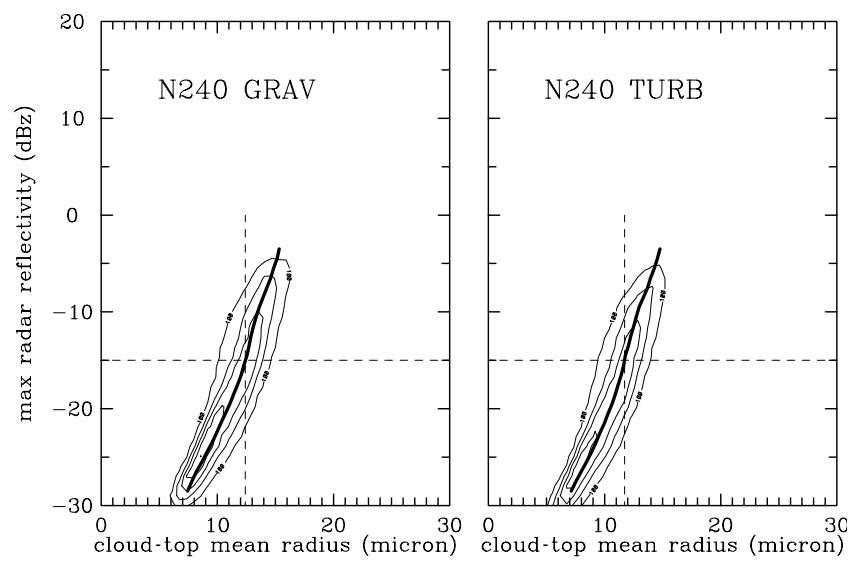

Figure 9. Joint histograms of the maximum radar reflectivity in the model column vs. the cloud-top mean radius of cloud droplets for GRAV and TURB N240 cases. The contours mark the data point density (with contour interval of 200 starting at 100) and the thick solid lines depict the mean relationship implied by the histogram. Dashed horizontal line represents the $-15 \mathrm{dBz}$ threshold and the dashed vertical line marks the mean radius corresponding to the $-15 \mathrm{dBz}$ threshold.

erties of the cloud field focusing on the impact of the turbulent collision kernel and with references to the impacts investigated previously (e.g., the entrainment-evaporation feedback, Xue and Feingold, 2006). Subsequently we asked the question whether remote sensing observations (e.g., from space, as in Suzuki et al., 2013) would be capable of supporting the simulated impact of the small-scale cloud turbulence on rain development.

When averaged over significant time (say, several hours), macroscopic effects are relatively small and in agreement with previous studies. Clouds featuring small cloud droplets (e.g., the N240 cases) yield a smaller time-averaged cloud fraction and cloud cover because of a more rapid droplet evaporation near cloud edges. Clouds featuring large cloud droplets (e.g., the GRAV and TURB N30 cases) produce significant amount of drizzle/rain and show a distinct increase of the number of deeper clouds because of the condensate offloading in the upper parts of the cloud field. These impacts are consistent with the analysis of the cloud buoyancy (the density potential temperature, Figs. 2, 3, and 4) that shows an increased contribution of positively buoyant cloudy updrafts for the N30 case in the upper parts of the cloud field. The N240 cases feature an increased contribution of cloud-edge downdrafts, arguably because of more rapid evaporation of cloud droplets in this case. The systematic shift between cloudy updrafts and cloud-edge downdrafts seems to provide an explanation for the changes of the cloud-top height distribution.

The relatively small macroscopic impact documented here and its contrast to a significant effect on surface precipitation agree with general conclusions of Franklin (2014; F14
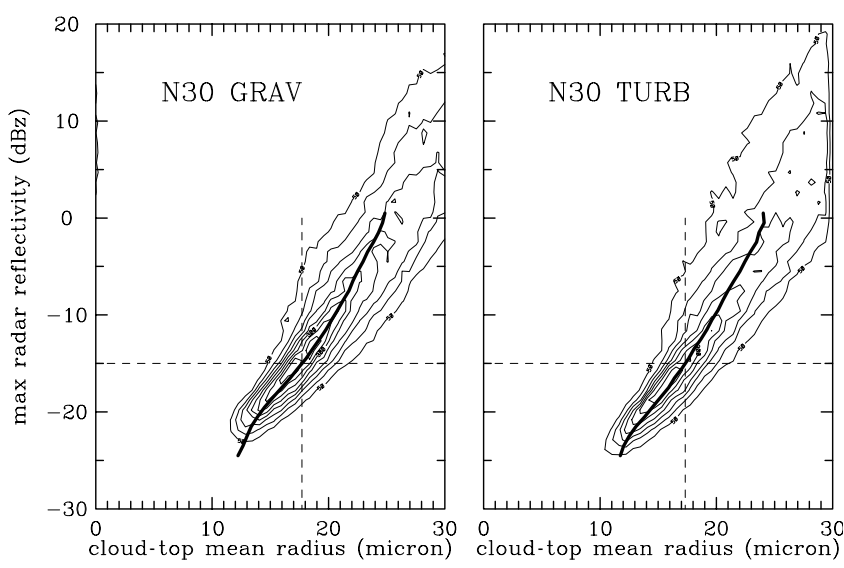

Figure 10. As Fig. 9, but for the N30 cases. The contour interval and the starting contour are 50 .

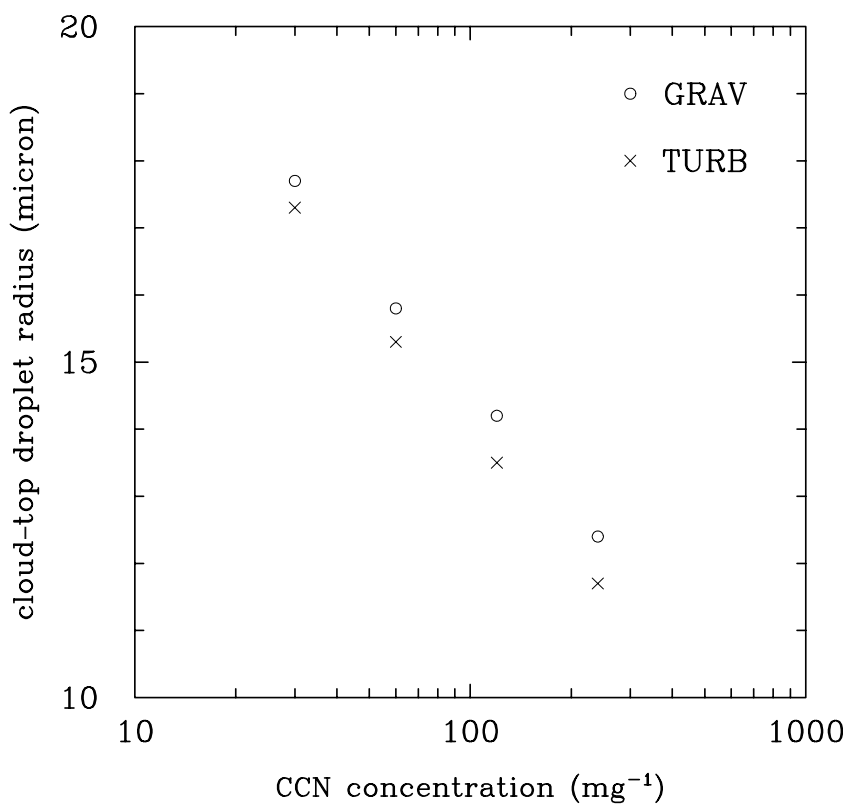

Figure 11. Cloud-top mean droplet radius for the $-15 \mathrm{dBz}$ radar reflectivity threshold as a function of the $\mathrm{CCN}$ concentration for GRAV and TURB simulations.

hereinafter). F14 applied a double-moment bulk warm-rain scheme with turbulent enhancement of the autoconversion parameterization to shallow convection case based on RICO (Rain In Cumulus over Ocean) field observations (see Figs. 3, 5 and 6 therein). However, specific interpretations of model results differ significantly between our study and that of F14. Applying similar statistical methods as used here (i.e., timeand space-averaged conditionally sampled cloud fields) F14 argues that the simulated feedback between clouds and their environment involves modifications of the parameterized turbulent kinetic energy budget and entrainment. We believe that alluding to uncertain subgrid-scale parameterizations to explain the feedback is not needed and that the explanation 
documented herein and in WGWA13 involving condensate offloading is also valid for the F14 simulations. This points to the fundamental differences between single cloud simulations (where time evolutions of relevant cloud statistics can be easily obtained) and cloud field simulations that are typically analyzed through domain-averaged statistics with cloud life cycles averaged over many cloud realizations. As illustrated by Fig. 5 herein and in agreement Fig. 3 in F14, simulations with a significant drizzle/rain feature more liquid water in the upper parts of the cloud field. This, however, does not contradict the condensate offloading mechanism, but can be explained by effects of the resolved dynamics, that is, more clouds reaching upper parts of the convection layer when the turbulent kernel is used as documented by the cloud-top distributions (see Fig. 1 herein).

As in similar previous studies (e.g., Xue and Feingold, 2006; Stevens and Seifert, 2008; WGWA13, F14) the simulated impacts are difficult to quantify. One reason is a significant temporal variability of the mean cloud field as illustrated by several figures in WGWA13; see also Fig. 6 herein and Fig. 4 in F14. The other is because of different evolutions of the cloud field - even if initiated from the same initial conditions - resulting from the exponential separation of solution trajectories for a nonlinear dynamical system. A novel way forward was recently proposed by Grabowski $(2014,2015)$. The idea is to use two sets of thermodynamic variables driven by different microphysical schemes or by a single scheme with different scheme parameters. The first set is coupled to the dynamics, and the second set is applied diagnostically, that is, driven by the flow but without the feedback on the flow dynamics. Having the two schemes operating in the same flow pattern allows extracting even a minuscule impact with high confidence. The methodology is referred to as the microphysical piggybacking. Grabowski (2014) demonstrated the capability of this methodology in large eddy simulations of shallow convection, whereas Grabowski (2015) applied microphysical piggybacking to investigate the hypothesized invigoration of deep convection in polluted environments. We plan to apply such a methodology to bin microphysics simulations in the future.

Attempting to compare model results discussed here to in situ aircraft observations of clouds developing in environments with contrasting aerosol loadings (e.g., Prabha et al., 2012) highlights the fundamental problem concerning assessment of indirect aerosol effects on clouds and precipitation. In the simulation, one can apply exactly the same temperature and moisture profiles and vary only aerosols, whereas variable aerosol conditions in nature typically involve different environmental conditions. Prabha et al. (2012) show that premonsoon clouds developing in the environment with high aerosol concentrations are also accompanied by the low environmental humidity that affects cloud dynamics through entrainment. If considered in our study, different environmental relative humidity would most likely lead to additional effects, such as even more rapid evaporation of polluted clouds. One can also argue that atmospheric measurements are not accurate enough to obtain either true environmental profiles or precise temperature and moisture tendencies due to larger-scale horizontal and vertical advection that provide forcing for moist convection. Problems with confident separation of aerosol effects from other factors affecting cloud development (e.g., meteorological conditions) highlight the fundamental difficulty with assessments of indirect aerosol effects from observations. Yet another issue concerns the fact that correlations seen in the field data are often incorrectly interpreted as a sign of causality, which does not have to be the case.

We also presented results of the analysis targeting the issue whether remote sensing using satellite observations can provide support for the simulated effects of small-scale turbulence on drizzle/rain development in shallow convective clouds. Putting aside very basic differences between large eddy simulations and satellite observations (such as the spatial resolution, for example), model results suggest that including effects of small-scale turbulence (i.e., moving from GRAV to TURB simulations) leads to only a small modification of parameters that can be associated with drizzle and rain development for prescribed CCN conditions. For instance, the probability of precipitation for a given liquid water path does show systematic increase from GRAV to TURB simulations, but the increase is relatively small (below $10 \%$ ). Such an increase would be difficult to quantify in observations when all uncertainties in estimation of aerosol environment in which clouds develop are taken into account. Similarly, there is only a small change of the mean cloud-top radius that corresponds to the onset of drizzle/rain, below $1 \mu \mathrm{m}$. Such a change is small when compared to the impact of CCN concentration, where the radius increases from about 12 to about $18 \mu \mathrm{m}$ between $\mathrm{N} 240$ and N30 simulations.

An obvious drawback of satellite observations is that only a limited set of parameters can be derived from both passive and active remote sensing, and these are often not the best to link cloud properties and precipitation processes, not to mention uncertainties associated with the retrievals themselves. For instance, the liquid water path provides a measure of the cloud vertical extent (and perhaps of entrainment) but it excludes any microphysical information. Cloud optical thickness (extensively used in analyses presented in Suzuki et al. (2013) and in other studies), incorporating a mixture of bulk and microphysical properties, is poorly suited for our purpose. This is because one expects precipitation to increase with the cloud depth (and thus with the liquid water path) and with the droplet size. However, optical depth increases with the liquid water path, but decreases with the increase of the droplet size. In other words, the relationship between the cloud optical depth and precipitation is not unique because deeper clouds with smaller droplets can produce the same precipitation as shallower clouds featuring larger drops. A variable that can be retrieved from satellite observations 
that increases with the increase of both the cloud depth and droplet size would be more useful.

Because of the satellite footprint (e.g., around $1.8 \mathrm{~km}$ for CloudSat), perhaps stratiform clouds, such as the subtropical stratocumulus, might be better candidates for comparing effects of cloud turbulence between model simulations and remote sensing. However, effects of turbulence are expected to be significantly weaker in stratocumulus clouds because of the lower turbulence intensity (this is in agreement with simulations reported in Franklin, 2014). We plan to perform large eddy simulations of a drizzling stratocumulus using the microphysical piggybacking (Grabowski, 2014, 2015) and the model applied in the current study. We will report results of such simulations in the future.

Acknowledgements. This work was partially supported by the US NSF through grants AGS-1139743, OCI-0904534, and OCI-0904449. W. W. Grabowski was partially supported by the NSF Science and Technology Center for Multiscale Modeling of Atmospheric Processes (CMMAP; managed by Colorado State University under cooperative agreement ATM-0425247) and by the DOE ASR grant DE-SC0008648. L.-P. Wang also acknowledges visitor support from the NCAR's Mesoscale \& Microscale Meteorology (MMM) Division and Geophysical Turbulence Program (GTP). Computer time at NCAR was provided by NSF through MRI grants CNS-0421498, CNS-0420873, CNS-0420985. The National Center for Atmospheric Research is sponsored by the National Science Foundation.

Edited by: C. Hoose

\section{References}

Albrecht, B. A.: Aerosols, cloud microphysics, and fractional cloudiness, Science, 245, 1227-1230, 1989.

Cooper, W. A., Lasher-Trapp, S. G., and Blyth, A. M.: The influence of entrainment and mixing on the initial formation of rain in a warm cumulus cloud, J. Atmos. Sci., 70, 1727-1743, 2013.

Damiani, R. and Vali, G.: Evidence for tilted toroidal circulations in cumulus, J. Atmos. Sci., 64, 2045-2060, 2007.

Franklin, C. N.: The effects of turbulent collision-coalescence on precipitation formation and precipitation-dynamical feedbacks in simulations of stratocumulus and shallow cumulus convection, Atmos. Chem. Phys., 14, 6557-6570, doi:10.5194/acp-14-65572014, 2014.

Grabowski, W. W.: Indirect impact of atmospheric aerosols in idealized simulations of convective-radiative quasi-equilibrium, J. Climate, 19, 4664-4682, 2006.

Grabowski, W. W.: Extracting microphysical impacts in large eddy s imulations of shallow convection. J. Atmos. Sci., 71, 4493-4499, 2014.

Grabowski W. W.: Untangling microphysical impacts on deep convection applying a novel modeling methodology, J. Atmos. Sci., submitted, 2015.
Grabowski, W. W. and Clark, T. L.: Cloud-environment interface instability, Part II: Extension to three spatial dimensions, J. Atmos. Sci., 50, 555-573, 1993.

Grabowski, W. W. and Morrison, H.: Indirect impact of atmospheric aerosols in ide- alized simulations of convective-radiative quasiequilibrium. Part II: Double-moment microphysics, J. Climate, 24, 1897-1912, 2011.

Grabowski, W. W. and Wang, L.-P.: Diffusional and accretional growth of water drops in a rising adiabatic parcel: effects of the turbulent collision kernel, Atmos. Chem. Phys., 9, 2335-2353, doi:10.5194/acp-9-2335-2009, 2009.

Grabowski, W. W., Andrejczuk, M., and Wang, L.-P.: Droplet growth in a bin warm-rain scheme with Twomey CCN activation, Atmos. Res., 99, 290-301, 2011.

Holland, J. Z. and Rasmusson, E. M.: Measurements of the atmospheric mass, energy, and momentum budgets over a 500 kilometer square of tropical ocean, Mon. Weather Rev., 101, 44-55, 1973.

Khain, A., Prabha, T. V., Benmoshe, N., Pandithurai, G., and Ovchinnikov, M.: The mechanism of first raindrops formation in deep convective clouds, J. Geophys. Res. Atmos., 118, 91239140, doi:10.1002/jgrd.50641, 2013.

Pawlowska, H. and Brenguier, J. L.: An observational study of drizzle formation in stratocumulus clouds for general circulation model (GCM) parameterizations, J. Geophys. Res., 108, 8630, doi:10.1029/2002JD002679, 2003.

Pincus, R. and Baker, M.: Effect of precipitation on the albedo $s$ usceptibility of clouds in the marine boundary layer, Nature, 372, 250-252, 1994.

Prabha, T. V., Patade, S., Pandithurai, G., Khain, A., Axisa, D., Pradeep-Kumar, P., Maheshkumar, R. S., Kulkarni, J. R., and Goswami, B. N.: Spectral width of premonsoon and monsoon clouds over Indo-Gangetic valley, J. Geophys. Res., 117, D20205, doi:10.1029/2011JD016837, 2012.

Prusa, J. M., Smolarkiewicz, P. K., and Wyszogrodzki, A. A.: EULAG, a computational model for multiscale flows, Comput. Fluids, 37, 1193-1207, 2008.

Rosenfeld, D.: Suppression of rain and snow by urban and industrial air pollution, Science 287, 1793-1796, 2000.

Rosenfeld, D. and Gutman, G.: Retrieving microphysical properties near the tops of potential rain clouds by multispectral analysis of AVHRR data, Atmos. Res., 34, 259-283, 1994.

Siebesma, A. P., Bretherton, C. S., Brown, A., Chlond, A., Cuxart, J., Duynkerke, P. G., Jiang, H., Khairoutdinov, M., Lewellen, D., Moeng, C.-H., Sanchez, E., Stevens, B., and Stevens, D.: A large eddy simulation intercomparison study of shallow cumulus convection, J. Atmos. Sci., 60, 1201-1219, 2003.

Stevens, B.: On the growth of layers of nonprecipitaning cumulus convection, J. Atmos. Sci., 64, 2916-2931, 2007.

Stevens, B. and Feingold, G.: Untangling aerosol effects on clouds and precipitation in a buffered system, Nature, 461, 607-613, 2009.

Stevens, B. and Seifert, A.: Understanding macrophysical outcomes of microphysical choices in simulations of shallow cumulus convection, J. Meteorol. Soc. Jpn., 86a, 143-162, 2008.

Suzuki, K., Stephens, G. L., and Lebsock, M. D.: Aerosol effect on the warm rain formation process: satellite observations and modeling, J. Geophys. Res. Atmos., 118, 170-184, 2013. 
Twomey, S.: Pollution and the planetary albedo, Atmos. Environ., 8, 1251-1256, 1974.

Twomey, S.: The influence of pollution on the shortwave albedo of clouds, J. Atmos. Sci., 34, 1149-1152, 1977.

Van Zanten, M. C., Stevens, B., Vali, G., and Lenschow, D. H.: Observational of drizzle nocturnal marine stratocumulus, J. Atmos. Sci., 62, 88-106, 2005.

Wang, L.-P., Xue, Y., Ayala, O., and Grabowski, W. W.: Effects of stochastic coalescence and air turbulence on the size distribution of cloud droplets, Atmos. Res., 82, 416-432, 2006.

Warner, J.: A reduction in rainfall associated with smoke from sugar-cane fires - An inadvertent weather modification?, J. Appl. Meteor., 7, 247-251, 1968.
Wyszogrodzki, A. A., Grabowski, W. W., and Wang, L.-P.: Activation of cloud droplets in bin-microphysics simulation of shallow convection, Acta Geophys., 59, 1168-1183, 2011.

Wyszogrodzki, A. A., Grabowski, W. W., Wang, L.-P., and Ayala, O.: Turbulent collision-coalescence in maritime shallow convection, Atmos. Chem. Phys., 13, 8471-8487, doi:10.5194/acp-138471-2013, 2013.

Xue, H. and Feingold, G.: Large-eddy simulations of trade wind cumuli: investigation of aerosol indirect effects, J. Atmos. Sci., 63, 1605-1622, 2006. 